\title{
Is Surgery Better Than Conservative Treatment for Proximal Humeral Fracture: A Systematic Review and Meta-Analysis
}

\author{
Dawei Gong \\ Guangzhou University of Chinese Medicine \\ Tianye Lin \\ Guangzhou University of Chinese Medicine \\ Jingli Xu \\ Zhanjiang First Hospital of Traditional Chinese Medicine \\ Xiaobo Wang \\ Wendeng Orthopaedic and Traumatologic Hospital of Shandong Province \\ Jian Li \\ Guangzhou University of Chinese Medicine \\ Heran Zhao \\ Guangzhou University of Chinese Medicine \\ Chi Zhou \\ The First Affiliated Hospital of Guangzhou University of Chinese Medicine \\ Leilei Chen \\ The Third Affiliated Hospital of Guangzhou University of Chinese Medicine \\ Haibin Wang ( $\nabla$ whb@gzucm.edu.cn ) \\ Guangzhou University of Chinese Medicine https://orcid.org/0000-0002-0879-9991
}

\section{Research article}

Keywords: proximal humeral fracture, conservative treatment, surgical treatment, efficacy

Posted Date: August 5th, 2020

DOI: https://doi.org/10.21203/rs.3.rs-53383/v1

License: (9) (1) This work is licensed under a Creative Commons Attribution 4.0 International License. Read Full License 


\section{Abstract}

Background: Previous studies had compared the effectiveness of surgical and conservative treatment in proximal humeral fracture (PHF), suggesting that both treatments were effective for displaced fractures. However, which treatment is more effective, especially in the elderly patient population, remains controversial to date. This study aims to evaluate the efficacy of the two treatment methods, including functional outcome scores, complications, etc.

Methods: We searched four databases (MEDLINE, Web of Science, EMBASE, Cochrane Library) from the inception of the databases to March 2020. Within the scope of the search, the publication time and language of the relevant literatures were not limited. The meta-analysis directly compared the results and complications of the two groups and subgroups.

Results: We included 11 comparative studies into our meta-analysis. The contents of the study included 7 randomized controlled trials (RCTs) and 4 non-randomized controlled trials (nRCTs). The pooled data demonstrated that there was no significant difference in postoperative Constant score between surgical and conservative treatment in the RCT subgroup, but there were differences among the nRCT and prosthesis subgroup. Although there was no significant difference between the surgery and conversation group in the major postoperative complications, the subgroup analysis showed fewer complications in the joint prosthesis replacement group.

Conclusion: Both treatments could provide better clinical results for patients. The joint prosthesis replacement may offer additional benefits in terms of reduced complications and postoperative function. Furthermore, due to the increasing number of prosthesis replacements and the advent of the aging age, we should consider the individual differences between patients and enrich the clinical efficacy through the personal experience of surgeons before choosing treatment options.

\section{Background}

Proximal humeral fracture (PHF) account for $4 \%$ $5 \%$ of all fractures, $26 \%$ of shoulder fractures[1]. It's concentrated in elder with osteoporosis and is the third most common in older patients, followed by femoral neck fractures and distal radius fractures[2, 3]. We often use Neer classification criteria to assess the severity of this fracture injury. According to the classification, most of the patients had 3-part and 4-part fractures[4]. In the course of clinical treatment, kirschner wires, plate, prosthesis replacement and other treatment methods had been successfully reported in cases.

Most patients with PHF were of minor displacement type, and if there was no significant probability of complications in clinical practice, they would be treated conservatively[5-7]. The same thing happened in elders. Therefore, the effect of conservative treatment was not obviously controversial according to 1-part and 2-part fractures in Neer classification. In contrast, many surgeons had different views on the conservative and surgical treatment of fractures more severe than the Neer 3-part classification[8]. As internal fixation continues to improve, different design schemes and application effects will exist based on different concepts. In the past, the application of plate and prosthesis in the unstable fractures such as 3-part and 4-part, especially in the elderly population, has been more controversial. In recent years, metaanalysis had been conducted to continuously evaluate this problem[9]. At present, reverse shoulder arthroplasty (RSA) has been applied more and more widely. The recent meta-analysis related to surgery and conservative treatment had not been included in this surgical method, and the comparison of relevant contents in the past two years had not been reported, which couldn't make us more intuitive to understand the latest treatment dynamics and effect analysis. The purpose of this study is to evaluate the efficacy of surgical and conservative treatment by exploring the advantages and disadvantages of major functional score and postoperative complications of PHF.

\section{Methods}

\section{Search Strategy}

We conducted a comprehensive and systematic review of the published literatures on account of the Preferred Reporting Items for Systematic Reviews and Meta-Analysis (PRISMA) statement. All the authors had passed the research protocol through a web conference before we carried out this literature search. In order to ensure that the study process is not disturbed, we selected two authors (Xiaobo Wang, Jian Li) who were from different regions to carry out all the searches independently and identify relevant studies of clinical outcomes and complications from the inception of the databases to March 2020 in the EMBASE (through OvidSP), MEDLINE (through PubMed), CENTRAL (Cochrane Central Register of Controlled Trials, through the Cochrane-Library) and SCl (through Web of Science) databases. All articles were free of language restrictions. We also didn't restrict the publication dates of articles. Before the manuscript was completed, we searched the relevant contents again, and no new articles were found. We used key words combined with MeSH terms according to different database formats to research. Differences were solved by discussion. The detailed search strategy is presented in Appendix 1. In addition, We also hand-searched the reference lists of all articles related to retrieval to identify other potentially available data. 


\section{Inclusion and Exclusion Criteria}

The search results of the systematic review were independently evaluated by the two authors by means of viewing the full text or abstract. Any controversy between the two authors in the process was finally resolved by the intervention of the third author (Chi Zhou). The included articles were RCTs and nRCTs, which directly compared the efficacy of surgery and conservative treatment of adult PHF followed up for at least 1 year. Surgical intervention included plate, prosthesis replacement and others, while conservative treatment included non-invasive operation, such as bandages, slings and so on. The main outcome measures (Constant score) should be included in the study results, and the postoperative complications should be expressed. Cadaver and repeat studies, case reports, abstracts, letters to the editor, commentary reports, reviews, animal experiments, etc. were excluded. No comparison between the two treatments was included in the literature and incomplete outcome data were also excluded.

\section{Data Extraction}

Data containing information such as basic information and main results were independently and carefully summarized from the included studies and filled into a table designed before the study by two evaluators (Xiaobo Wang, Jian Li). All differences between them finally reached a consensus through discussion. This standardized extraction table included the following: (1) study information (ie, author, year of publication, country, journal, and design of study); (2) study population information (ie, age, gender, design number of patients, and fracture classification); (3) surgical implant, conservative treatment, incision method and follow-up; (4) primary outcomes (ie, function score and complications).

\section{Study Quality Assessment}

In terms of research methodology, the COCHRANE tool was used to assess the risk of bias to determine whether biases affected the final outcome in the RCTs. The nRCTs were evaluated using the NOS scale. These studies were evaluated independently by the two authors (Leilei Chen, Jingli Xu). Disagreement between them were resolved through discussion to reach a consensus or by inviting the third author to participate in the discussion.

\section{Statistical Analysis}

For dichotomous outcomes, such as complications, the risk ratio (RR) and 95\% confidence intervals (Cls) were used to evaluate the relevant studies. Mean difference (MD) was used for continuous variables, including constant score. For some special continuous variables in the articles, such as means and range, we used statistical algorithms to make standard deviations estimates. In the process of studies, only means and standard deviations could be included in the analysis. In the results, $\mathrm{p}$ and $\mathrm{I}^{2}$ values were used to analyze whether there was heterogeneity. When $\mathrm{p}>0.1$ or $\mathrm{I}^{2}<50 \%$, a fixed-effect model was adopted to the meta-analysis, when on the contrary, a random-effect mode was applied. Sensitivity analyses were performed to evaluate the stability of the results (if necessary), and subgroup analyses were performed based on RCT, nRCT, implants. Forest plots were used to show the results of individual studies and respective pooled estimates of effect size. The publication bias of any outcomes was evaluated by funnel plots. If the sample size was small, this may not be carried out. All statistical analysis processes were ran by Review Manager (version 5.3.5 for Windows). Since STATA software could display the p-value of funnel plot, which could better quantify the result, all funnel plots were ran by STATA software (version 15.0 for Windows) during this process.

\section{Results}

\section{Study Selection}

We identified 3,841 potentially relevant articles searched from four electronic databases based on our previous search strategy. A total of potentially references $(n=1836)$ were extracted by endnote software and manual inspection. After reading the titles and abstracts, 1949 papers were excluded. We read the full text of the remaining 56 articles, and 45 were excluded for the following reasons: other surgical methods, lack of raw or complete data, randomized trial designs, letters, case reports, commentaries, and reviews. According to the inclusion criteria, 11 final publications published from 1997 to 2019 were selected through full-text reading and included in the meta-analysis (Figure 1). The 11 articles included complete data comparing the results of surgical and non-surgical treatment of PHF. There were 590 patients, including 298 in the surgical group and 292 in the conservative group. According to the different research methods and surgical treatment methods, we classified the paper into the groups of random and non-random sets, plate internal fixation and prosthesis replacement. A screening of the reviews through the full text of the 11 articles, no additional research was found to be available.

\section{Study Characteristics and Quality}


Among the 590 patients in these 11 studies, most of them were elderly, mostly females. The preoperative diagnostic classification was mainly focused on Neer classification of 3-part and 4-part. All of the included articles reported on the authors, year of publication, country, treatment, follow-up, fracture classification, functional score, etc. (Table 1)

Table 1 Characteristics of inclued studies comparing outcomes for surgery versus conservative treatment for PHF

\begin{tabular}{|c|c|c|c|c|c|c|c|c|c|}
\hline \multirow[t]{2}{*}{ Author } & \multirow[t]{2}{*}{ Year } & \multirow[t]{2}{*}{ Country } & \multirow[t]{2}{*}{ Design } & \multicolumn{2}{|c|}{ Mean age (SD,range), year } & \multirow{2}{*}{$\begin{array}{l}\text { Female } \\
\text { patients } \\
\text { (SG/CG) }\end{array}$} & \multirow{2}{*}{$\begin{array}{l}\text { Fracture } \\
\text { classification }\end{array}$} & \multirow{2}{*}{$\begin{array}{l}\text { Follow- } \\
\text { up(months) }\end{array}$} & \multirow{2}{*}{$\begin{array}{l}\text { Number } \\
\text { of } \\
\text { follow- } \\
\text { up } \\
\text { (SG/CG) }\end{array}$} \\
\hline & & & & SG & CG & & & & \\
\hline $\begin{array}{l}\text { Karol } \\
\text { Zyto }\end{array}$ & 1997 & Sweden & RCT & $73 \pm 7.5$ & $75 \pm 6.7$ & $18 / 17$ & Neer 3,4-part & 50 & $14 / 15$ \\
\hline $\begin{array}{l}\text { Per } \\
\text { Olerud HA }\end{array}$ & 2011 & Sweden & RCT & $75.8(58-90)$ & $77.5(60-92)$ & $23 / 24$ & Neer 4-part & 24 & $24 / 25$ \\
\hline $\begin{array}{l}\text { Per } \\
\text { Olerud LP }\end{array}$ & 2011 & Sweden & RCT & $72.9(56-92)$ & $74.9(58-88)$ & $24 / 24$ & Neer 3-part & 24 & $27 / 26$ \\
\hline $\begin{array}{l}\text { Harm W. } \\
\text { Boons }\end{array}$ & 2012 & $\begin{array}{l}\text { The } \\
\text { Netherlands }\end{array}$ & RCT & $76.4(5.6)$ & $79.9(7.7)$ & $24 / 23$ & Neer 4-part & 12 & $24 / 23$ \\
\hline $\begin{array}{l}\text { Tore } \\
\text { Fjalestad }\end{array}$ & 2014 & Norway & RCT & $\begin{array}{l}72.2(60- \\
86)\end{array}$ & $\begin{array}{l}73.1(60- \\
88)\end{array}$ & $20 / 24$ & $\mathrm{AO} \mathrm{B} 2 / \mathrm{C} 2$ & 24 & $23 / 19$ \\
\hline $\begin{array}{l}\text { Antti P. } \\
\text { Launonen }\end{array}$ & 2019 & Finland & RCT & $\begin{array}{l}72(7.4,60- \\
90)\end{array}$ & $\begin{array}{l}73(7.7,60- \\
86)\end{array}$ & $41 / 39$ & Neer 2-part & 24 & $33 / 39$ \\
\hline $\begin{array}{l}\text { Yaiza } \\
\text { Lopiz }\end{array}$ & 2019 & Spain & RCT & $82 \pm 3.4$ & $85 \pm 4.8$ & $25 / 26$ & Neer 3,4-part & 12 & $29 / 30$ \\
\hline $\begin{array}{l}\text { Cheng } \\
\text { Biao }\end{array}$ & 2005 & China & retrospective & 64(56 71区 & $66 \rrbracket 60 \sim 62 \rrbracket$ & $16 / 13$ & Neer 3,4-part & 24 & $20 / 20$ \\
\hline FAN Rong & 2012 & China & retrospective & $74.5(63 \sim 80)$ & 75.3(66 82) & $10 / 11$ & Neer 3,4-part & 16 & $20 / 15$ \\
\hline $\begin{array}{l}\text { Massimo } \\
\text { Innocenti }\end{array}$ & 2013 & Italy & retrospective & $\begin{array}{l}73.92 \pm \\
6.01\end{array}$ & $77.47 \pm 6.95$ & $\mathrm{NC} / \mathrm{NC}$ & $\begin{array}{l}\text { Neer 2,3,4- } \\
\text { part }\end{array}$ & 7.1 years & $23 / 19$ \\
\hline $\begin{array}{l}\text { Matthieu } \\
\text { Chivot }\end{array}$ & 2019 & France & retrospective & 77 (70-92) & $79.2(70-92)$ & $22 / 30$ & Neer 3,4-part & $\begin{array}{l}\text { SG:31.8 } \\
\text { CG:32.1 }\end{array}$ & $28 / 32$ \\
\hline
\end{tabular}

Table 1 (continued) 


\begin{tabular}{|c|c|c|c|c|c|c|c|}
\hline \multirow[t]{2}{*}{ Author } & \multirow[t]{2}{*}{ Implant } & \multirow[t]{2}{*}{$\begin{array}{l}\text { Conservative } \\
\text { treatment }\end{array}$} & \multirow[t]{2}{*}{$\begin{array}{l}\text { Incision } \\
\text { method }\end{array}$} & \multicolumn{2}{|c|}{$\begin{array}{l}\text { Number of complications } \\
\text { (nonunion and osteonecrosis } \rrbracket\end{array}$} & \multicolumn{2}{|c|}{$\begin{array}{l}\text { Function Score } \\
\text { (Constant score) }\end{array}$} \\
\hline & & & & SG & CG & SG & CG \\
\hline \multirow[t]{2}{*}{ Karol Zyto } & \multirow{2}{*}{$\begin{array}{l}\text { tension-band, K- } \\
\text { wires }\end{array}$} & \multirow[t]{2}{*}{ sling } & \multirow[t]{2}{*}{ deltopectoral } & 1. AVN (1) & \multirow[t]{2}{*}{0} & \multirow[t]{2}{*}{$60 \pm 19$} & \multirow[t]{2}{*}{$65 \pm 15$} \\
\hline & & & & 2. Nonunion (1) & & & \\
\hline \multirow{2}{*}{$\begin{array}{l}\text { Per Olerud } \\
\text { HA }\end{array}$} & \multirow{2}{*}{$\begin{array}{l}\text { Global Fx } \\
\text { prosthesis }\end{array}$} & \multirow[t]{2}{*}{ sling } & \multirow[t]{2}{*}{ deltopectoral } & \multirow[t]{2}{*}{0} & 1. AVN (3) & \multirow[t]{2}{*}{$48.3 \pm 16.4$} & \multirow[t]{2}{*}{$49.6 \pm 20.5$} \\
\hline & & & & & 2. Nonunion (1) & & \\
\hline $\begin{array}{l}\text { Per Olerud } \\
\text { LP }\end{array}$ & Philos plate & sling & deltopectoral & AVN (3) & Nonunion (1) & $61.0 \pm 19.2$ & $58.4 \pm 23.1$ \\
\hline $\begin{array}{l}\text { Harm W. } \\
\text { Boons }\end{array}$ & $\begin{array}{l}\text { Global1FX } \\
\text { endoprosthesis }\end{array}$ & $\begin{array}{l}\text { shoulder } \\
\text { immobilizer }\end{array}$ & deltopectoral & Nonunion (2) & Nonunion (3) & $64 \pm 15.8$ & $60 \pm 17.6$ \\
\hline $\begin{array}{l}\text { Tore } \\
\text { Fjalestad }\end{array}$ & LCT-plate & $\begin{array}{l}\text { Velpeau } \\
\text { bandage }\end{array}$ & deltopectoral & Nonunion (1) & Nonunion (2) & $74.4 \pm 29.4$ & $74.4 \pm 22.9$ \\
\hline $\begin{array}{l}\text { Antti P. } \\
\text { Launonen }\end{array}$ & Philos plate & $\begin{array}{l}\text { collar-cuff or } \\
\text { sling }\end{array}$ & $\mathrm{NC}$ & 0 & 0 & $68.0 \pm 18.4$ & $66.0 \pm 20.6$ \\
\hline $\begin{array}{l}\text { Yaiza } \\
\text { Lopiz }\end{array}$ & prosthesis & sling & deltopectoral & 0 & 0 & $61.7 \pm 12.1$ & $55.7 \pm 12.4$ \\
\hline Cheng Biao & LPHP & bandage & deltopectoral & 0 & 0 & $75 \pm 19$ & $65 \pm 14$ \\
\hline \multirow[t]{2}{*}{ FAN Rong } & \multirow[t]{2}{*}{ LPHP } & \multirow[t]{2}{*}{$\begin{array}{l}\text { Splint or } \\
\text { plaster }\end{array}$} & \multirow[t]{2}{*}{ deltopectoral } & $\begin{array}{l}\text { 1.Osteonecrosis } \\
\text { (1) }\end{array}$ & \multirow[t]{2}{*}{ Osteonecrosis (1) } & \multirow[t]{2}{*}{$66.8 \pm 11.8$} & \multirow[t]{2}{*}{$64.7 \pm 9.9$} \\
\hline & & & & 2. Nonunion (1) & & & \\
\hline $\begin{array}{l}\text { Massimo } \\
\text { Innocenti }\end{array}$ & k-wires & brace & $\mathrm{NC}$ & 0 & 0 & $80.67 \pm 5.24$ & $76.39 \pm 9.03$ \\
\hline $\begin{array}{l}\text { Matthieu } \\
\text { Chivot }\end{array}$ & $\begin{array}{l}\text { Reverse } \\
\text { Shoulder } \\
\text { System }\end{array}$ & $\begin{array}{l}\text { elbow } \\
\text { immobilized }\end{array}$ & deltopectoral & 0 & $\begin{array}{l}\text { 1.Osteonecrosis (3) } \\
\text { 2. Nonunion (1) }\end{array}$ & $56.5 \pm 14.3$ & $50.5 \pm 12.9$ \\
\hline
\end{tabular}

SG凹sugery group, CG: conservation group, SD: standard deviation, RCT: randomized controlled trial, NC: not clear

The study included 7 RCTs[10-16], 4 retrospective comparative studies[17-20], of which 5 were plate implants and 4 were prosthesis replacements for PHF. Most surgical incisions were through the deltopectoral incision. Conservative treatment techniques mainly included sling and bandage.

The quality assessment of these studies demonstrated a moderate risk of bias (Figure 2, Figure 3 and Table 2).

Table 2 Quality assessment for the included nRCTs by means of NOS scale

\begin{tabular}{|c|c|c|c|c|c|c|c|c|c|c|}
\hline Study & Item 1 & Item 2 & Item 3 & Item 4 & Item $5 \mathrm{~A}$ & Item 5B & Item 6 & Item 7 & Item 8 & Score \\
\hline Cheng Biao 2005 & प & प & प & & प & प & & प & प & 7 \\
\hline FAN Rong 2012 & प & प & $\square$ & & ] & प & & प & & 6 \\
\hline Massimo Innocenti 2013 & प & प & $\square$ & & 口 & $\square$ & ] & प & प & 8 \\
\hline Matthieu Chivot 2019 & [ & [ & [ & & [ & [ & [ & [ & [ & 8 \\
\hline
\end{tabular}

Items in above table: 1 . Whether there was a representation of the exposed cohort; 2 . The non-exposed cohort study came from the same community as the exposed cohort; 3 . Ascertainment of exposure studies had been conducted based on records or investigations; 4 . No outcome events were studied before the study began; 5A. comparability of cohorts (based on the design or analysis) about age; 5B. comparability of cohorts regarding disease extent and its duration; 6 . Assess outcomes based on relevant evidence; 7 . Follow-up was adequate for outcome; 8 . adequacy of follow-up of cohorts.

\section{Outcome}




\section{Functional outcome}

Constant score is one of the most commonly used functional indicators in patients with PHF. Due to the significant influence of different experimental design methods and different implant surgery methods on the postoperative, we conducted subgroup analysis on them respectively, hoping to make more effective observation at the initial stage.

In this study, there were 7 RCT literatures, which were tested for heterogeneity, $\mathrm{I}^{2}=0 \%<50 \%$, and the $\mathrm{p}$ value in the $\mathrm{Q}$ test was $0.77>0.1$, indicating that there was no heterogeneity among the selected articles in this study, and fixed effect was selected for meta-analysis. Sensitivity analysis was conducted on 7 research literatures, and none of them had a significant impact on the results of this meta-analysis, indicating that this study had good stability (Figure 4). It could be clearly seen from Figure 5 that the funnel plot of the RCT group was basically symmetrical, and the bias test at the same time showed that $\mathrm{p}$ value $=0.23>0.05$, and there was no publication deviation in the article of this group. Similarly, there was no heterogeneity among the articles in the nRCT group. Subgroups in forest plot shown that RCT group $Z=1.4, p=0.16>0.05$, there was no significant difference between the conservation group and surgery group, but nRCT trails showed significant difference in Constant score $(p=0.004<0.05)$.

Among the 11 literature studies, most treatments were treated with sling or bandage. The surgery group could be divided into two methods (except Karol Zyto[10] and Massimo Innocenti[19] using k-wires): internal fixation plate and prosthesis replacement. Therefore, we divided the study into two subgroups based on built-in differences. In the comparison between the plate group (conservation and surgery group), Chi ${ }^{2}=$ $0.18, P=0.67>0.05$, there was no significant difference in the functional score of the PHFs (Figure 6) and the prosthesis group $Z=2.35, p=$ $0.02<0.05$, with significant difference, which may be caused by the small sample size of this subgroup, and the use of Reverse Shoulder System implant by Matthieu Chivot[20] and Yaiza Lopiz[15], while the use of hemiarthroplasty by Per Olerud[11] and Harm w. Boons[14]. Although both were arthroplasty, there were still some differences in postoperative functional scores between the two surgical methods.

\section{Complications}

We extracted most common complications of PHFs from 11 articles: nonunion and osteonecrosis. In 7 studies with complications, RR of the 7 studies was 0.67 , the $95 \%$ confidence interval was 0.32 to $1.41, Z=1.04, P=0.30>0.05$, and there was no significant difference in fracture nonunion and osteonecrosis between the two treatment from Figure 7. The funnel plot was basically symmetrical, and the bias test $p=0.76>$ 0.05 . There was no deviation, as we could see from Figure 8. Meanwhile, there was no significant heterogeneity in subgroups, but $Z=2.14, P=$ $0.03<0.05$ between the subgroups, Figure 9 demonstrated that there was a significant difference in the prosthesis group in terms of complications.

\section{Discussion}

This meta-analysis included 11 studies (7 RCTs and $13 \mathrm{nRCTs}$ ) that evaluated 590 patients and compared postoperative functional scores and complications between surgery and conservative treatment. The pooled data shown no difference in functional scores between the two treatment modalities in RCT group and plate group. In general, there was no significant difference in the incidence of common complications between the surgery and conservation group, however, there were a significant difference in the subgroup of prosthesis group.

The proximal humeral anatomy is complex, fractures are extremely prone to occur during trauma[21]. It is believed that conservative treatment will not cause secondary trauma, and the medical cost is low, so it is suitable for the elderly or patients with intolerance to surgery. Although conservative treatment could lead to complications such as fracture displacement and joint stiffness, some scholars reported that nonsurgical treatment had a good clinical efficacy. Den et al.[22] treated comminuted PHFs in the elderly with humeral head replacement and nonsurgical methods respectively, and found that the long-term efficacy of non-surgical treatment was better than the former. At present, with the improvement of technology, LPHP and PHILOS plates were gradually applied and popularized. In particular, the design of PHILOS plate could break through the shortcomings of large incision exposure and severe local blood flow destruction in the traditional plate exposure process[23]. At the same time, it could also achieve reliable fixation effect through the cross-locking technology of multi-angle screws. The design of rotator cuff repair hole more achieves the combination of bone and soft tissue, plays the role of internal fixation bracket, and promotes the healing of fractures[24, 25]. In contrast to intramedullary nailing and prosthesis replacement techniques, surgeons are more likely to master plate internal fixation, which is more adaptable to PHF and easier to popularize. Nevertheless, Doshi et al.[26] proposed that the application of plate technology was based on individual differences of patients, and patients should be strictly selected and familiar with relevant anatomy. But Stanbury SJ[27] believed that RSA was superior to internal fixation.

In clinical practice, we often decide whether to use prosthesis based on age and degree of fracture comminution. When using different types of prosthesis, we found that the clinical effect of hemiarthroplasty often reached the concept of "all or nothing", with good efficacy in some patients and poor in others. But RSA could often achieve better results. Emmanuel Maugendre[28] believed that RSA had unique advantages 
in the treatment of PHF in elderly, with a 1-year survival rate that was 7-13\% higher than that of femoral neck fractures. Jason Ferrel[29] agreed that RSA significantly improved forward shoulder flexion (range of motion greater than $10^{\circ}$ ) and had a relatively low revision rate (0.93\%) compared to hemiarthroplasty. In this meta-analysis, according to the complications described in the literature[11, 14, 15, 20], we found RSA compared to hemiarthroplasty had a lower incidence of complications after surgery, Clark, NJ.[30] clinical trials also proved the point, at the same time, they thought primary RSA was effective in the treatment of PHF, lower in medical and surgical complications, RSA was also effective in patients over 80 years of age after a comprehensive evaluation. However, RSA is not a panacea, and it has its own limitations. For example, Cho $\mathrm{CH}[31]$ believed that we should pay great attention to the complications of acromion fractures that commonly occur after surgery. Since RSA is limited by glenoid loosening and instability, prosthesis implantation failure may occur, Song IS et al.[32] believed that hemiarthroplasty could better solve such problems, and postoperative follow-up score and joint range of motion were satisfactory.

Surgical treatment of PHF could be performed by different incision methods. In the meta-analysis we performed above, the extracted data shown that 9/11 studies used deltopectoral approach, and the other two were minimally invasive incisions[11, 16]. The choice of approach is determined by the experience of different surgeons that a particular incision is more effective, safer, or that they are better at operating a particular approach. Although the traditional deltopectoral approach had the advantage of showing clear intermuscular space, its exposure to the posterior displaced greater tuberosity was limited [33]. Guilherme Grisi Mouraria[34] demonstrated that the anterolateral approach could better expose the lateral surface of the humerus, which was conducive to the operation, but the axillary nerve injury and subacromial impingement were still complications that couldn't be ignored. Other scholars believed that the subacromion anterolateral approach through the deltoid muscle had the advantages of minimally invasive, clear exposure, and no significant difference with the traditional deltopectoral approach in terms of reduction quality[35]. Harmer LS et al. examined two commonly used surgical approaches from cadaver tests, and they also demonstrated that the deltopectoral approach provided a better exposure to the front operating markers, while the anterolateral acromial approach provided a better rear exposure[36].

Due to the anatomical complexity of PHF and the nature of the fractures within the joint, many clinical complications occur, such as arthritis, joint stiffness, fracture nonunion, osteonecrosis, pain, joint dysfunction, fracture displacement, infection, bone resorption, and so on. However, nonunion of fracture and osteonecrosis are the most common and most likely causes of secondary surgery. Therefore, we summarized and analyzed the data of these two complications. Boesmueller et al. reported the follow-up results of 286 patients with PHF treated with PHILOS plate in 2016, among which 60 patients had postoperative complications, with a complication rate of 39\%[37]区

A detailed analysis of the complications would help us to further guide the clinical work, Klug et al. performed RSA or open reduction and internal fixation with locking plate in 125 elderly with complicated PHF. Statistical analysis demonstrated that the incidence of postoperative complications in locking plate group was significantly higher than that in RSA group (15.8\%). Therefore, it was recommended to perform RSA in the first phase in elderly patients with complex PHF[38]. This conclusion was consistent with our understanding.

Although we took various measures to reduce the influence of additional factors on the analysis results, there were still many potential limitations in this meta-analysis. First of all, no matter what kind of design is included in the standard, there will be methodological defects, so it is easy to cause some studies to be ignored. We consulted with professional librarians to get a better retrieval strategy, so as to minimize the impact on the results. Second, we conducted a comprehensive evaluation of RCTs and nRCTs at the initial stage, especially in terms of complications, which may lead to the deviation of the results due to problems in the trial design. Therefore, the analysis of subgroup analysis could ensure the comparability and scientificity of the results. In this process, we also found that the results of RCTs were more complete, which proved the accuracy of the design scheme and method, and the trial literature without omissions and exclusions were more accurate for the overall assessment. Thirdly, based on the grouping of the built-in objects, the overall classification into the plate group and the prosthesis group would bring about some differences in the results. As time goes on, more and more effective methods gradually replace the traditional methods, and meta-analysis is a systematic review process, which inevitably integrates a variety of fixed surgical methods. The subgroup analysis of these two methods was adopted to reduce the difference of results caused by the diversity of treatment methods. Fourth, according to the statistics from the baseline data, many surgical methods would produce different complications, and the differences here were caused by various reasons such as fracture types, and differences in the patients under surgery, which brought difficulties to the statistics of data collection. We selected the most common cases of fracture nonunion and osteonecrosis as a summary of complications, reducing individual differences in content, although this method may lead to some variation. Fifth, different classification, people of all ages would have different results, we conducted a comprehensive meta-analysis which would inevitably face the problem above, however, the above analysis, the cases of baseline data embodied mostly elderly patients and Neer3, 4 type fracture, common clinical characteristic of PHF determined the particularity. The relative limitation of the scope also helped us to reduce the impact on the results to some extent.

This meta-analysis is the first of its kind to use RCT and nRCT, as well as the combination of plate internal fixation and prosthesis replacement groups. In the initial strategy formulation, in order to avoid omissions, we adopted a more complete retrieval than before. In this process, unlike most articles, we searched, extracted and evaluated by two authors from different regions, and discussed in controversial

Page 7/17 
cases through webinar, further reducing the influence of additional factors. Moreover, in the past two years, there had been no analysis of such content by any author. Nowadays, with the rapid update of implants and surgical techniques, meta-analysis that cannot be updated in time will obviously miss more important information comparisons. Therefore, our assessment results were more accurate and timely. All studies included a direct comparison of conservative versus surgical treatment for PHFs, and we rigorously evaluated their quality. We conducted this study based on the PRISMA statement.

\section{Conclusion}

Our meta-analysis shown no significant differences in major complications between conservative and surgical approaches for PHFs, but there were some differences in the subgroup analysis, such as postoperative scores for the nRCT group and the prosthesis implant group, and postoperative complications for the prosthesis replacement group. Each patient should be considered individually before choosing the surgical procedure. Surgeons using their personal clinical experience to make preoperative planning could reduce the incidence of surgical failure. However, this study remains relatively limited, and more large-scale clinical trials, systematic reviews will be necessary in the future to confirm these findings.

\section{Abbreviations}

PHF: proximal humeral fracture; RCT: randomized controlled trial; nRCT: non-randomized controlled trial; RSA: reverse shoulder arthroplasty; PRISMA: Preferred Reporting Items for Systematic Reviews and Meta-Analysis; RR: risk ratio; Cl: confidence interval; MD: Mean difference; SD: standard deviation; SG: surgery group; CG: conservation group NC: not clear.

\section{Declarations}

\section{Ethics approval and consent to participate}

Not applicable.

\section{Consent for publication}

Not applicable.

\section{Availability of data and materials}

All data and materials used in this research are freely available. All data generated or analysed during this study are included in this published article and its supplementary information files.

\section{Competing interests}

The authors declare that they have no competing interests.

\section{Funding}

This study was supported in part by National Natural Science Foundation of China (No. 81774339), Major Subject Research Project of Guangzhou University of Chinese Medicine in 2019 (NO. XK2019012).

\section{Authors' contributions}

Literature search and data extraction: XBW, JL. Study quality assessment: LLC, JLX. Statistics, data analysis and interpretation: HRZ, TYL. Drafting article: DWG, HBW. Critical revision of article: CZ. All authors read and approved the final manuscript.

\section{Acknowledgements}

We express our gratitude to Zehuai Wen (DME Specialist) and Shuaishuai Liu (Expert in English Linguistics) from the Guangzhou University of Chinese Medicine for their involvement in the search term.

\section{Author details}

${ }^{1}$ The First Clinical Medical School, Guangzhou University of Chinese Medicine, Guangzhou, Guangdong 510405, China. ${ }^{2}$ Lingnan Medical Research Center of Guangzhou University of Chinese Medicine, Guangzhou, Guangdong 510405, China. ${ }^{3}$ Department of Joint Orthopaedic, the First Affiliated Hospital, Guangzhou University of Chinese Medicine, Guangzhou, Guangdong 510405, China. ${ }^{4}$ The First Affiliated Hospital 
of Guangzhou University of Chinese Medicine. ${ }^{5}$ Wendeng Orthopaedic and Traumatologic Hospital of Shandong Province, Weihai, Shandong 264400, China. ${ }^{6}$ The Third Affiliated Hospital of Guangzhou University of Chinese Medicine, Guangzhou, Guangdong 510145, China.

${ }^{7}$ Zhanjiang First Hospital of Traditional Chinese Medicine, Zhanjiang, Guangdong 524000, China.

\section{References}

1. Palvanen M, Kannus P, Niemi S, Parkkari J. Update in the epidemiology of proximal humeral fractures. Clin Orthop Relat Res. Jan 2006;442:87-92.

2. Ortmaier R, Mattiassich G, Pumberger M, et al. Comparison between reverse shoulder arthroplasty and Humerusblock in three- and fourpart proximal humerus fractures in elderly patients. Int Orthop. Feb 2015;39(2):335-342.

3. Savin DD, Zamfirova I, lannotti J, Goldberg BA, Youderian AR. Survey study suggests that reverse total shoulder arthroplasty is becoming the treatment of choice for four-part fractures of the humeral head in the elderly. Int Orthop. Sep 2016;40(9):1919-1925.

4. Neer CS, 2nd. Four-segment classification of proximal humeral fractures: purpose and reliable use. J Shoulder Elbow Surg. Jul-Aug 2002;11(4):389-400.

5. Robinson CM, Stirling PHC, Goudie EB, MacDonald DJ, Strelzow JA. Complications and Long-Term Outcomes of Open Reduction and Plate Fixation of Proximal Humeral Fractures. J Bone Joint Surg Am. Oct 92019.

6. Court-Brown CM, McQueen MM. The impacted varus (A2.2) proximal humeral fracture: prediction of outcome and results of nonoperative treatment in 99 patients. Acta Orthop Scand. Dec 2004;75(6):736-740.

7. Lowry V, Bureau NJ, Desmeules F, Roy JS, Rouleau DM. Acute proximal humeral fractures in adults. J Hand Ther. Apr - Jun 2017;30(2):158-166.

8. Kancherla VK, Singh A, Anakwenze OA. Management of Acute Proximal Humeral Fractures. J Am Acad Orthop Surg. Jan 2017;25(1):4252.

9. Dai J, Chai Y, Wang C, Wen G. Meta-analysis comparing locking plate fixation with hemiarthroplasty for complex proximal humeral fractures. Eur J Orthop Surg Traumatol. Apr 2014;24(3):305-313.

10. Zyto K, Ahrengart L, Sperber A, Törnkvist H. Treatment of displaced proximal humeral fractures in elderly patients. Journal of Bone and Joint Surgery - Series B. 1997;79(3):412-417.

11. Olerud P, Ahrengart L, Ponzer S, Saving J, Tidermark J. Hemiarthroplasty versus nonoperative treatment of displaced 4-part proximal humeral fractures in elderly patients: A randomized controlled trial. Journal of Shoulder and Elbow Surgery. 2011;20(7):1025-1033.

12. Olerud P, Ahrengart L, Ponzer S, Saving J, Tidermark J. Internal fixation versus nonoperative treatment of displaced 3-part proximal humeral fractures in elderly patients: A randomized controlled trial. Journal of Shoulder and Elbow Surgery. 2011;20(5):747-755.

13. Fjalestad T, Hole M $\emptyset$. Displaced proximal humeral fractures: operative versus non-operative treatment-a 2-year extension of a randomized controlled trial. European Journal of Orthopaedic Surgery and Traumatology. 2014;24(7):1067-1073.

14. Boons HW, Goosen JH, van Grinsven S, van Susante JL, van Loon CJ. Hemiarthroplasty for humeral four-part fractures for patients 65 years and older: a randomized controlled trial. Clin Orthop Relat Res. Dec 2012;470(12):3483-3491.

15. Lopiz Y, Alcobía-Díaz B, Galán-Olleros M, García-Fernández C, Picado AL, Marco F. Reverse shoulder arthroplasty versus nonoperative treatment for 3- or 4-part proximal humeral fractures in elderly patients: a prospective randomized controlled trial. Journal of Shoulder and Elbow Surgery. 2019;28(12):2259-2271.

16. Launonen AP, Sumrein BO, Reito A, et al. Operative versus non-operative treatment for 2-part proximal humerus fracture: A multicenter randomized controlled trial. Plos Medicine. Jul 2019;16(7).

17. Cheng B, Lin JP, Chen ZR, Yao ZJ, Zhang C. Therapy of comminuted fracture of proximal humerus with locking proximal humerus plate. Fudan University Journal of Medical Sciences. 2005;32(1):92-94.

18. Fan Y, Wang S, Luo Y. [Effectiveness comparison of operative and non-operative treatment for complex proximal humeral fractures in elderly patients]. Zhongguo xiu fu chong jian wai ke za zhi $=$ Zhongguo xiufu chongjian waike zazhi = Chinese journal of reparative and reconstructive surgery. 2012;26(9):1029-1032.

19. Innocenti M, Carulli C, Civinini R, Matassi F, Tani M, Muncibì F. Displaced fragility fractures of proximal humerus in elderly patients affected by severe comorbidities: Percutaneous fixation and conservative treatment. Aging Clinical and Experimental Research. 2013;25(4):447-452.

20. Chivot M, Lami D, Bizzozero P, Galland A, Argenson J-N. Three- and four-part displaced proximal humeral fractures in patients older than 70 years: reverse shoulder arthroplasty or nonsurgical treatment? Journal of Shoulder and Elbow Surgery. Feb 2019;28(2):252-259.

21. Launonen AP, Sumrein BO, Lepola V. Treatment of proximal humerus fractures in the elderly. Duodecim. 2017;133(4):353-358. 
22. Den Hartog D, Van Lieshout EM, Tuinebreijer WE, et al. Primary hemiarthroplasty versus conservative treatment for comminuted fractures of the proximal humerus in the elderly (ProCon): a multicenter randomized controlled trial. BMC Musculoskelet Disord. May 25 2010;11:97.

23. Kavuri V, Bowden B, Kumar N, Cerynik D. Complications Associated with Locking Plate of Proximal Humerus Fractures. Indian J Orthop. Mar-Apr 2018;52(2):108-116.

24. Gonc U, Atabek M, Teker K, Tanriover A. Minimally invasive plate osteosynthesis with PHILOS plate for proximal humerus fractures. Acta Orthop Traumatol Turc. Jan 2017;51(1):17-22.

25. Moonot P, Ashwood N, Hamlet M. Early results for treatment of three- and four-part fractures of the proximal humerus using the PHILOS plate system. J Bone Joint Surg Br. Sep 2007;89(9):1206-1209.

26. Doshi C, Sharma GM, Naik LG, Badgire KS, Qureshi F. Treatment of Proximal Humerus Fractures using PHILOS Plate. J Clin Diagn Res. Jul 2017;11(7):Rc10-rc13.

27. Stanbury SJ, Voloshin I. Reverse shoulder arthroplasty for acute proximal humeral fractures in the geriatric patient: a review of the literature. Geriatr Orthop Surg Rehabil. Sep 2011;2(5-6):181-186.

28. Maugendre E, Gadisseux B, Chantelot C, et al. Epidemiology and mortality in older patients treated by reverse shoulder arthroplasty for displaced proximal humerus fractures. Orthop Traumatol Surg Res. Dec 2019;105(8):1509-1513.

29. Ferrel JR, Trinh TQ, Fischer RA. Reverse total shoulder arthroplasty versus hemiarthroplasty for proximal humeral fractures: a systematic review. J Orthop Trauma. Jan 2015;29(1):60-68.

30. Clark NJ, Samuelsen BT, Alentorn-Geli E, et al. Primary reverse shoulder arthroplasty in patients older than 80 years of age: survival and outcomes. Bone Joint J. Dec 2019;101-b(12):1520-1525.

31. Cho CH, Jung JW, Na SS, Bae KC, Lee KJ, Kim DH. Is Acromial Fracture after Reverse Total Shoulder Arthroplasty a Negligible Complication?: A Systematic Review. Clin Orthop Surg. Dec 2019;11(4):427-435.

32. Song IS, Jung D, Jeong U, An CH. Conversion of Failed Reverse Total Shoulder Arthroplasty to Hemiarthroplasty: Three Cases of Instability and Three Cases of Glenoid Loosening. Clin Orthop Surg. Dec 2019;11(4):436-444.

33. Choi S, Kang H, Bang H. Technical tips: dualplate fixation technique for comminuted proximal humerus fractures. Injury. Aug 2014;45(8):1280-1282.

34. Mouraria GG, Zoppi A, Kikuta FK, Moratelli L, Cruz MA, Etchebehere M. ANTEROLATERAL APPROACHES FOR PROXIMAL HUMERAL OSTEOSYNTHESIS: A SYSTEMATIC REVIEW. Acta Ortop Bras. May-Jun 2019;27(3):178-182.

35. Alberio RL, Del Re M, Grassi FA. Minimally Invasive Plate Osteosynthesis for Proximal Humerus Fractures: A Retrospective Study Describing Principles and Advantages of the Technique. Adv Orthop. 2018;2018:5904028.

36. Harmer LS, Crickard CV, Phelps KD, et al. Surgical Approaches to the Proximal Humerus: A Quantitative Comparison of the Deltopectoral Approach and the Anterolateral Acromial Approach. J Am Acad Orthop Surg Glob Res Rev. Jun 2018;2(6):e017.

37. Boesmueller S, Wech M, Gregori M, et al. Risk factors for humeral head necrosis and non-union after plating in proximal humeral fractures. Injury. Feb 2016;47(2):350-355.

38. Klug A, Wincheringer D, Harth J, Schmidt-Horlohe K, Hoffmann R, Gramlich Y. Complications after surgical treatment of proximal humerus fractures in the elderly-an analysis of complication patterns and risk factors for reverse shoulder arthroplasty and angular-stable plating. J Shoulder Elbow Surg. Sep 2019;28(9):1674-1684.

\section{Figures}




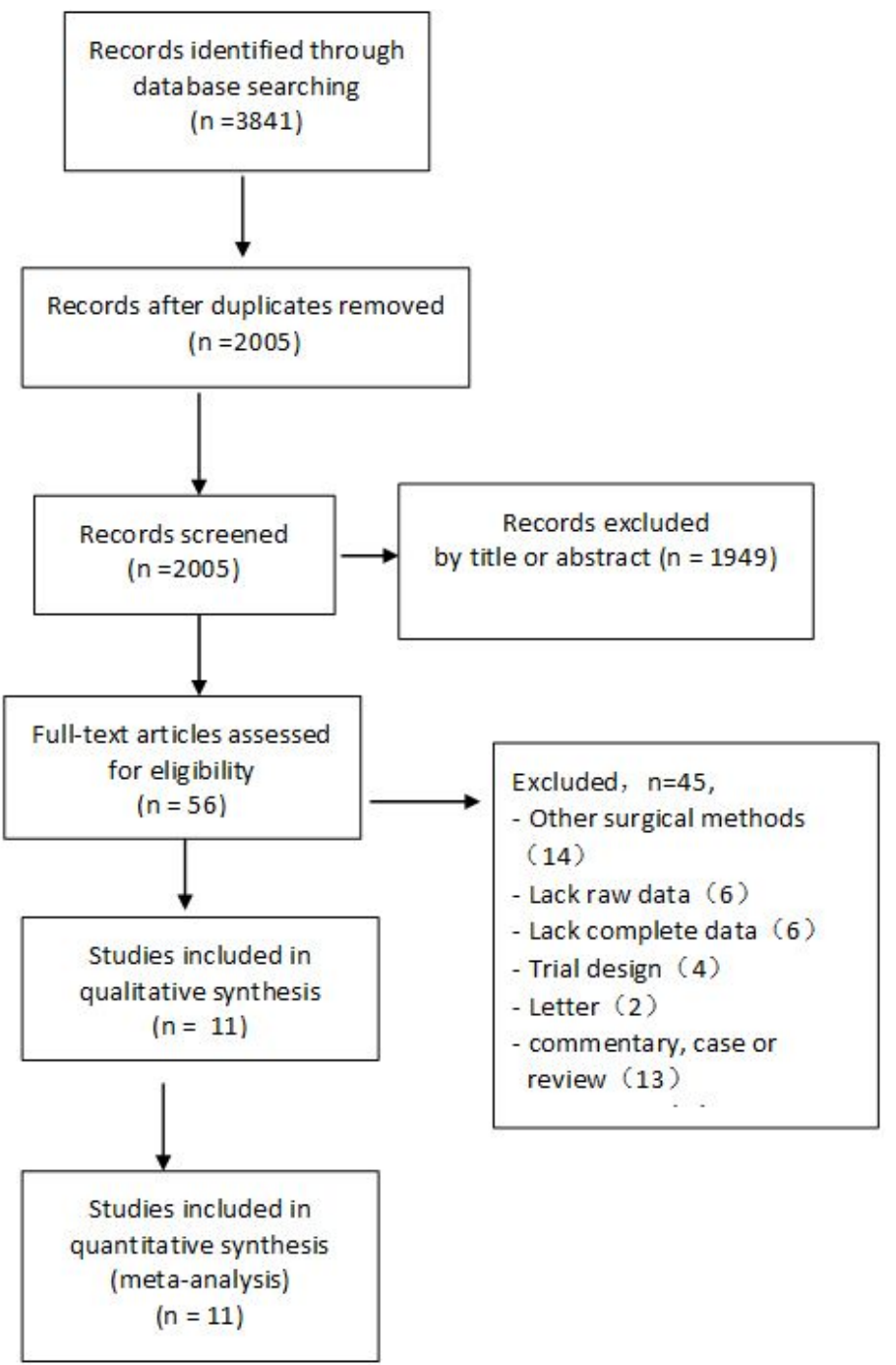

Figure 1

Study screening flow

Random sequence generation (selection bias)

Allocation concealment (selection bias)

Blinding of participants and personnel (performance bias)

Blinding of outcome assessment (detection bias)

Incomplete outcome data (attrition bias)

Selective reporting (reporting bias)

Other bias
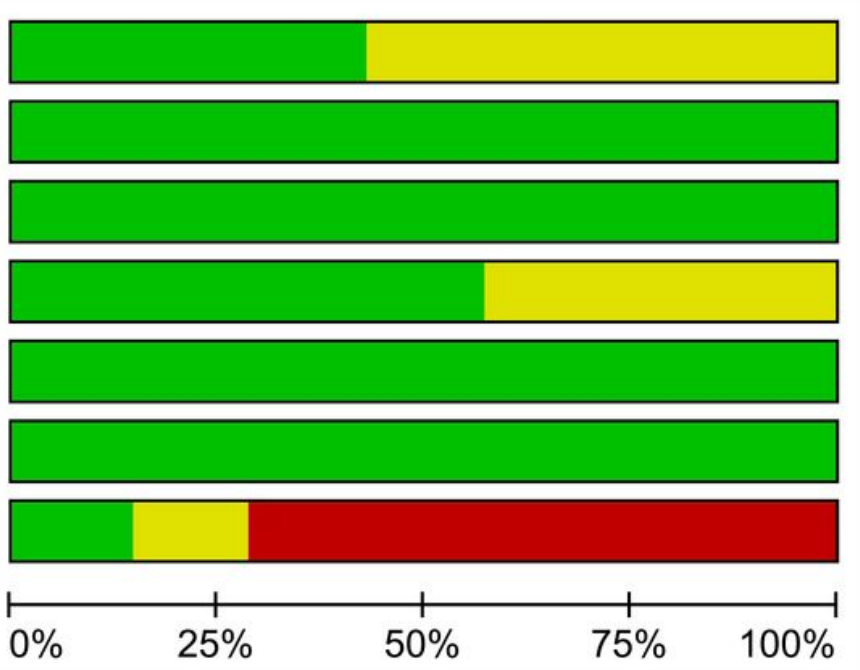


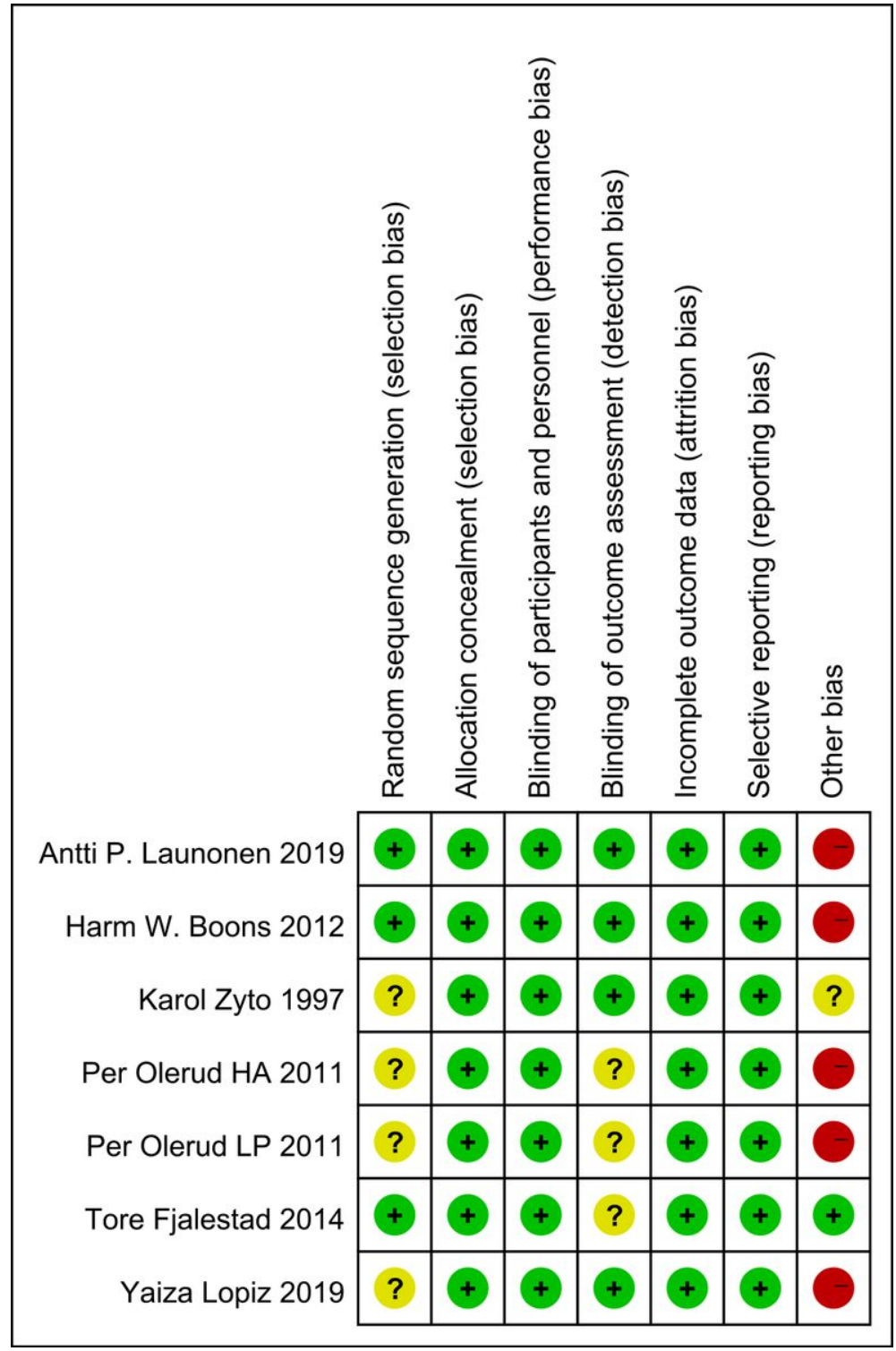

Figure 3

Risk of bias assessment for each study 


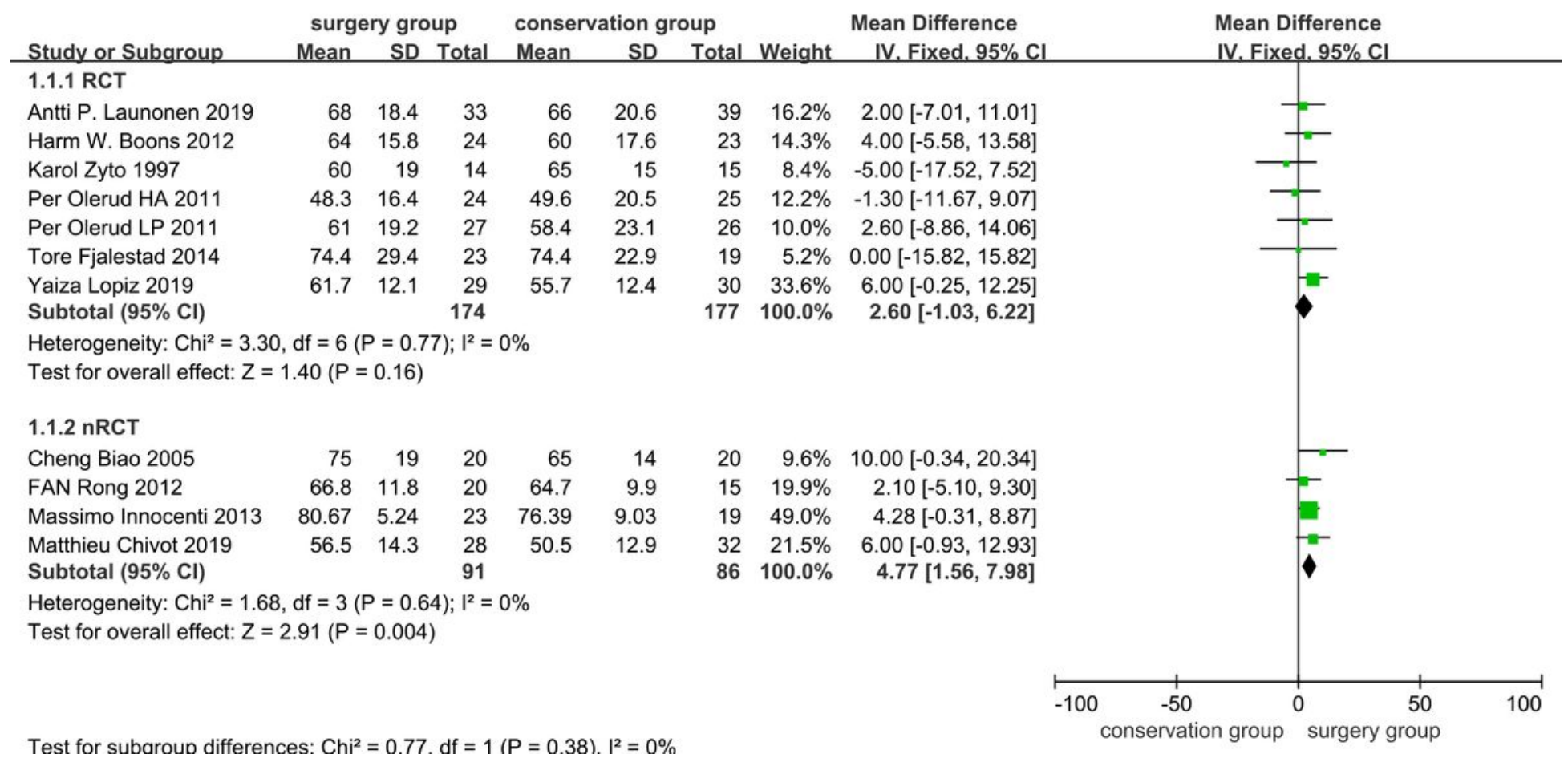

\section{Figure 4}

Forest plot representing functional scores for surgery versus conservative treatment in the RCT and nRCT groups 


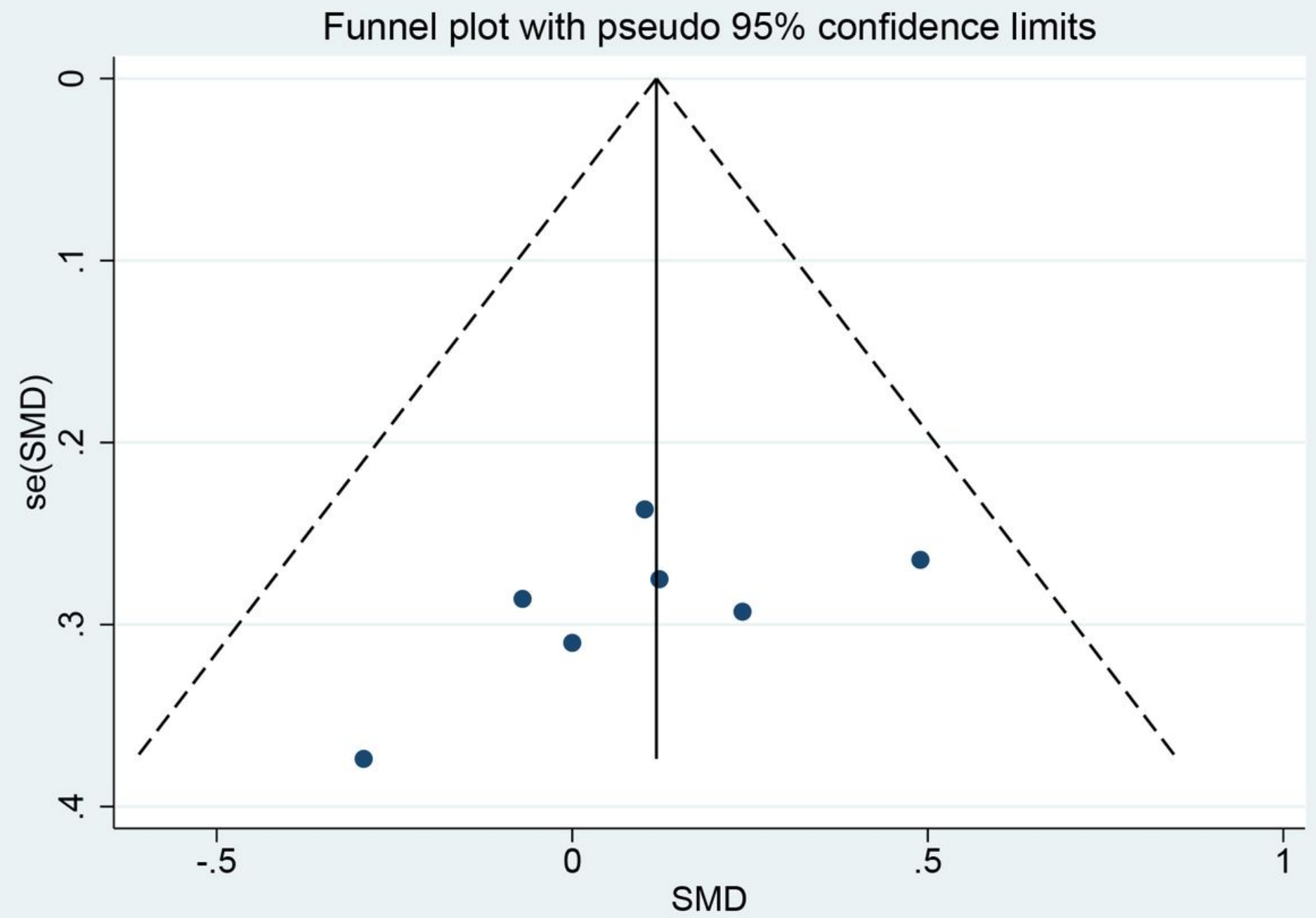

Figure 5

Symmetric funnel plot indicating the deviation in RCTs

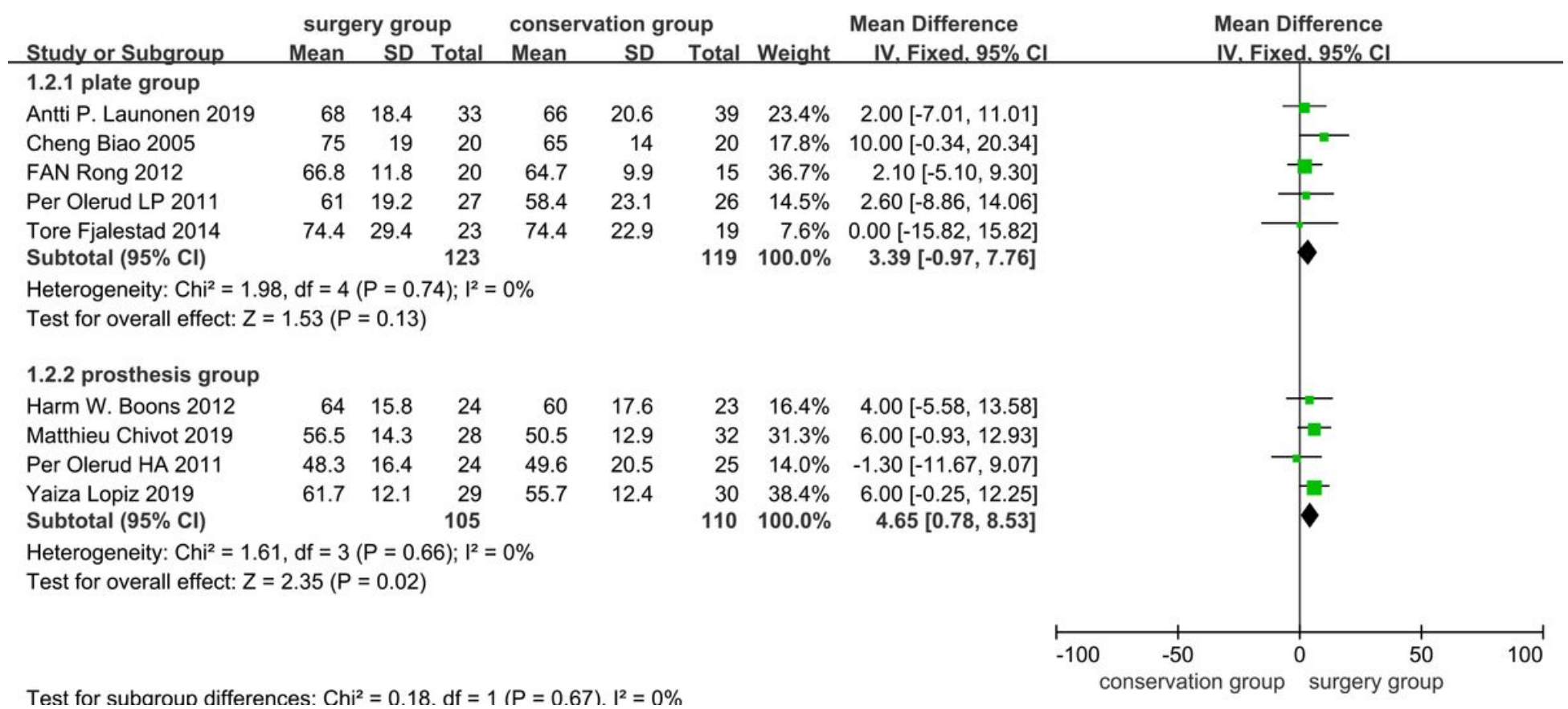


Figure 6

Forest plot representing functional scores (two implant methods) for surgery versus conservative treatment

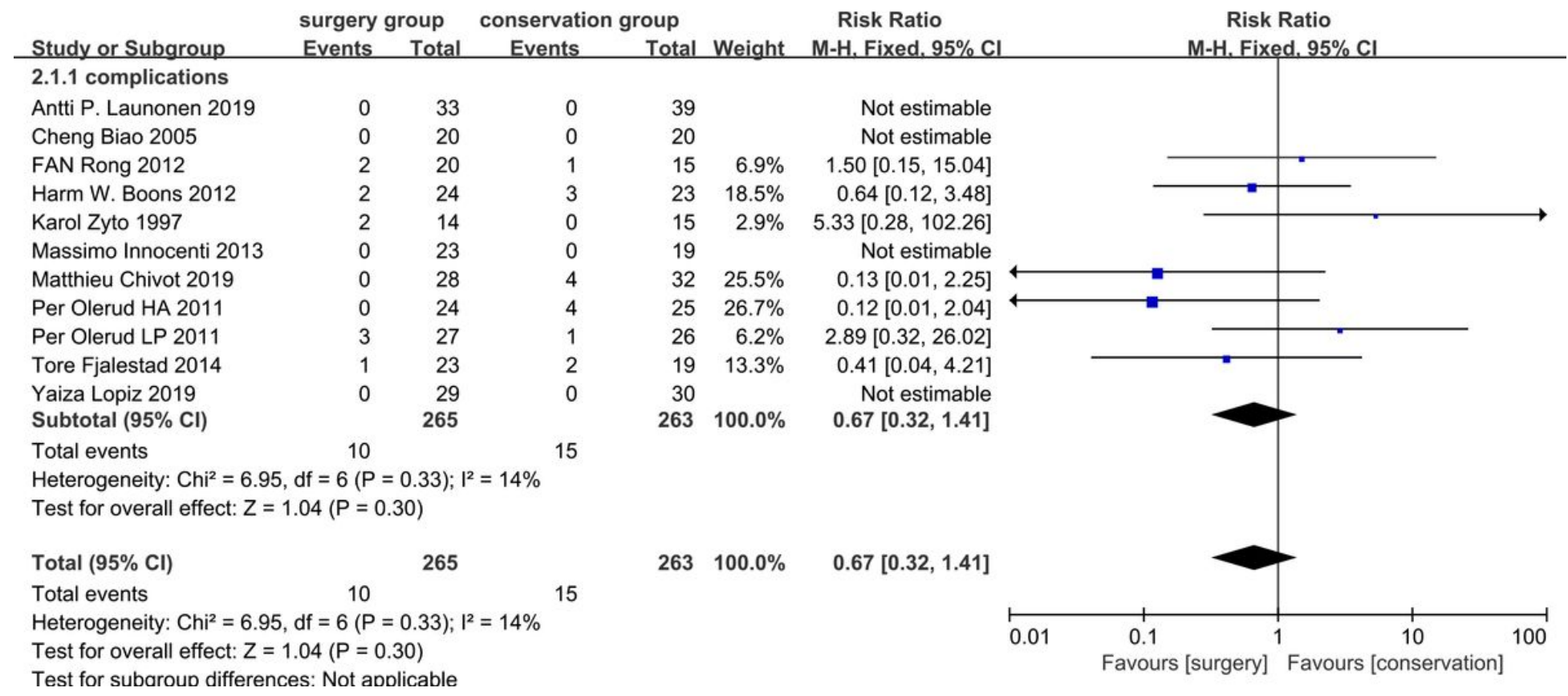

Figure 7

Forest plot representing the risk ratio of complications between the surgery group and conservation group 


\section{Funnel plot with pseudo 95\% confidence limits}

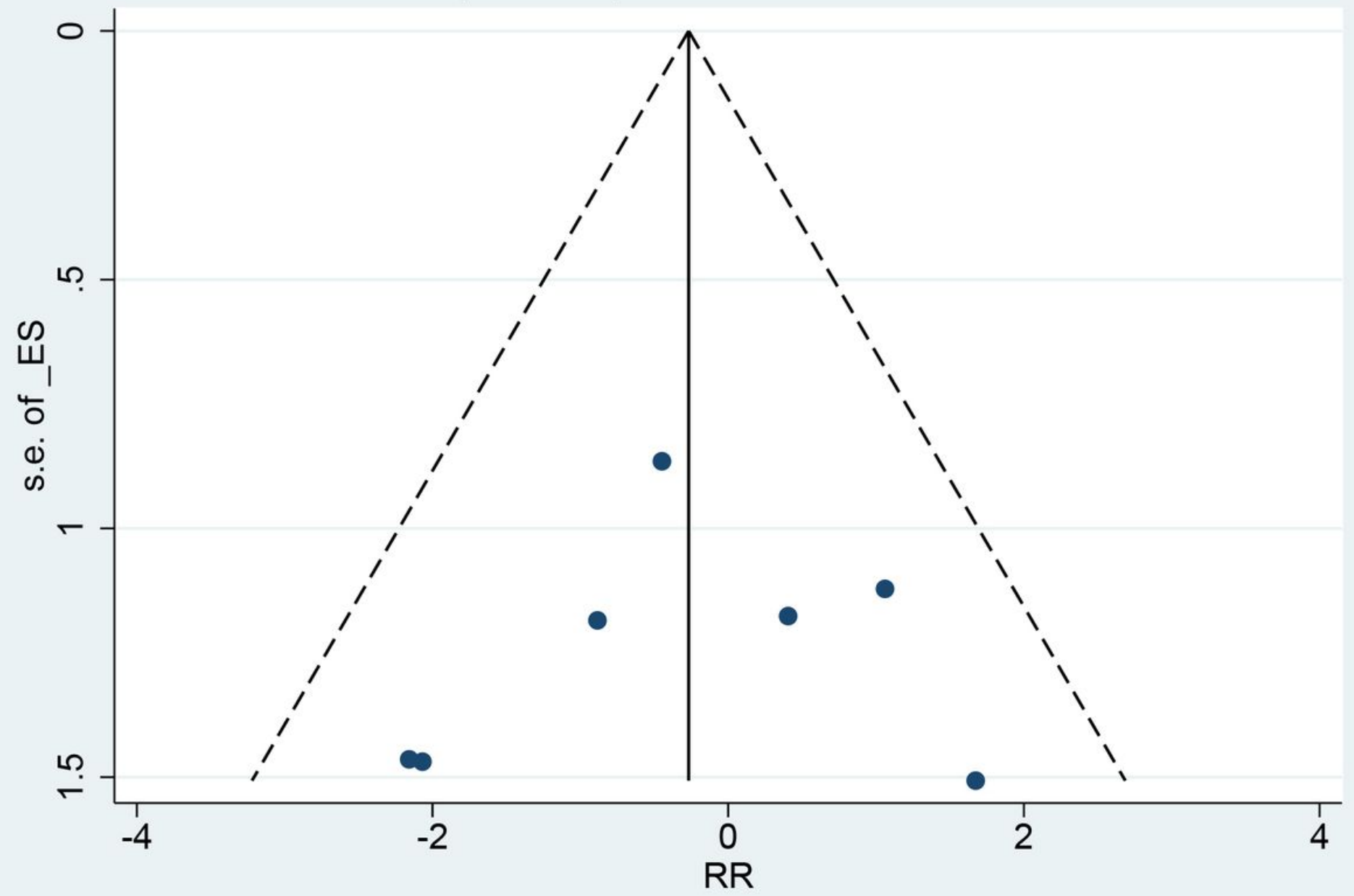

Figure 8

Symmetric funnel plot indicating the deviation in terms of complications 


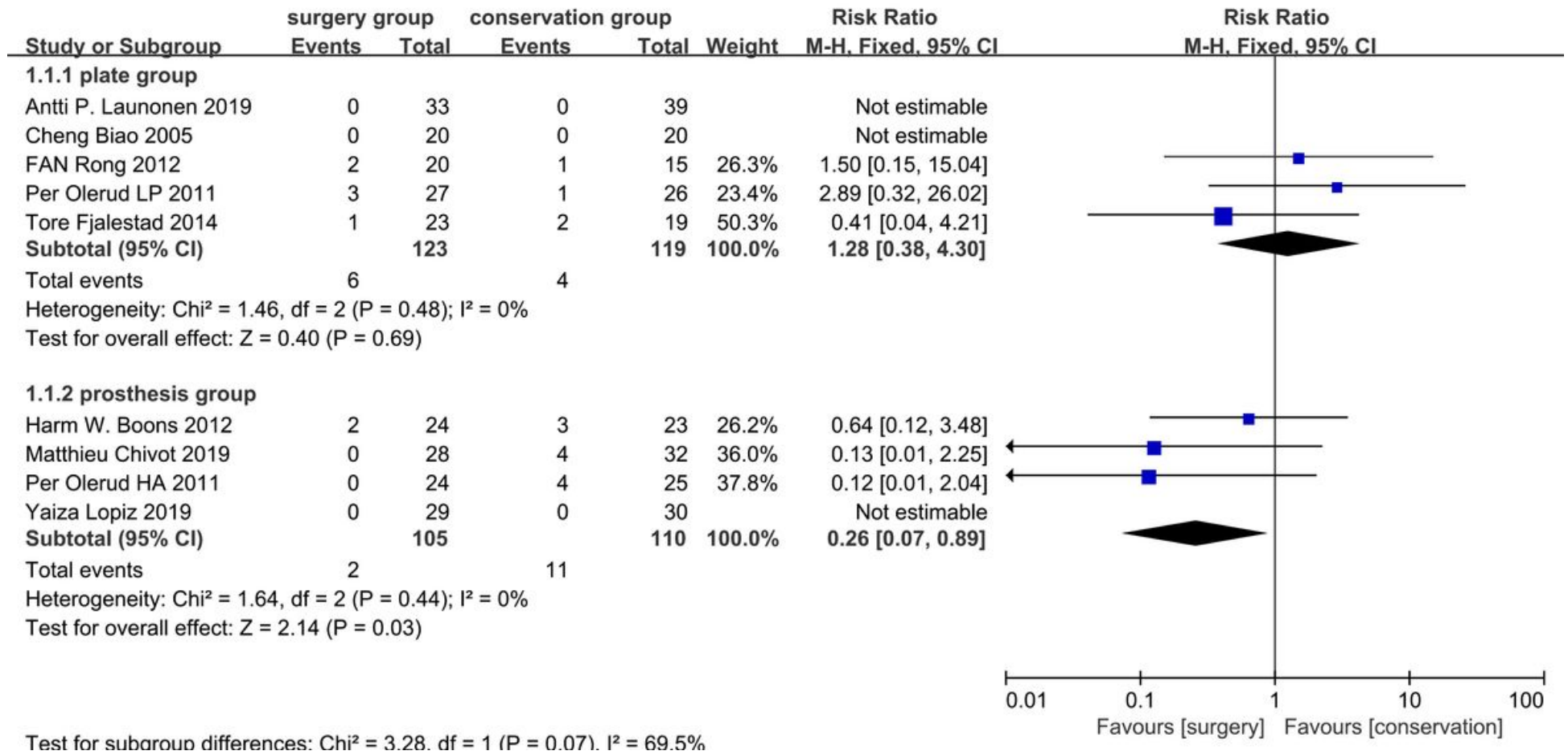

\section{Figure 9}

Forest plot representing the risk ratio of complications between the surgery group and conservation group

\section{Supplementary Files}

This is a list of supplementary files associated with this preprint. Click to download.

- Appendix1Searchstrategyaboutthismetaanalysis.docx

- Appendix1Searchstrategyaboutthismetaanalysis.docx

- Appendix2PRISMA2009checklist.doc

- Appendix2PRISMA2009checklist.doc 